\title{
Role of the Attribute Complexity in Adoption of Selected Dairy Innovations
}

\author{
G. Triveni ${ }^{1 *}$, G. R. K. Sharma ${ }^{1}$, Ch. Satyanarayana ${ }^{2}$, \\ K. Sarjan Rao ${ }^{1}$ and T. Raghunandhan ${ }^{3}$ \\ ${ }^{1}$ College of Veterinary Science, SVVU, Tirupati, India \\ ${ }^{2}$ College of Veterinary Science, Rajendranagar, Hyderabad, India \\ ${ }^{3}$ College of Veterinary Science, Korutla, Telangana, India \\ *Corresponding author
}

\begin{tabular}{|l|}
\hline Ke y w o r d s \\
Adoption, \\
Cognitive \\
complexity, \\
Adaptive \\
complexity
\end{tabular}

\section{A B S T R A C T}

\begin{abstract}
The present investigation is focused on the perceived attribute complexity, measured in terms of cognitive complexity and application complexity of the dairy innovations selected for the study. Cognitive complexity of the innovations is in turn measured as simple and complex and adaptability is measured based on its feasibility as adaptable and un adaptable for the nine innovations selected for the study. A sample of 360 dairy farmers were selected using simple random sampling technique from three districts i.e., Visakhapatnam, Krishna and Chittoor based on the highest livestock population from the three respective regions i.e., North coastal, Coastal and Rayalaseema regions of Andhra Pradesh. The innovations i.e., Package of practices for feeding and management of heifers, pregnant and lactating animals; Feeding of area specific mineral mixture; Cultivation and feeding of Azolla, Strategies for enhancement of milk yield and quality and Use of information and communication technologies were felt as simple and adaptable by majority $(90 \%)$ of the respondents while the innovations Formulation and feeding of complete feed blocks; Cultivation and feeding of hydroponic fodder; Use of milking machine and Marketing strategies to improve milk sales were found difficult for adoption by most $(53 \%)$ of the respondents.
\end{abstract}

\section{Introduction}

Innovation is "broadly defined as the implementation of ideas, practices or processes that are new or significantly improved within a particular environment and are intended to be beneficial" (ROGERS 1995).Innovation is a driving force for progress and development of any sector. Dairy farmers are continuously adapting their practices to new ecological, economic or social circumstances. Amongst others, changing prices, land scarcity, rain fed agriculture, new technological possibilities in dairying, remunerative price for milk and regular payments lead them to find and adopt new production methods in dairy sector to secure their livelihoods. However, farmers do not adopt innovations simultaneously, some adopting more rapidly than others, while some never adopt certain innovations. Farmers' perception towards the attributes of innovations/ recommended technologies if studied can provide useful information and 
help in improving the adoption rate and speeding up the whole diffusion process. Therefore, the present study was conducted to determine the role of the attribute 'Complexity' in influencing the perception of dairy farmers towards recommended dairy innovations for adoption decisions.

\section{Methodology}

Three regions of Andhra Pradesh viz., North coastal, Coastal and Rayalaseema regions were selected purposively for the study to ascertain the rate of adoption and diffusion of innovations by the dairy farmers in the state. One district was selected respectively from each region i.e., Visakhapatnam, Krishna and Chittoor based on highest livestock population and from each district and two mandals and from each mandal two villages were selected through simple random sampling technique.

Thus a total 18 villages were selected and 20 farmers from each village ranking best in the adoption of innovations were selected constituting a sample of 360 farmers for the study. In the present investigation 'Compatibility' is measured as the degree to which particular dairy innovation is consistent with existing values and past experiences of the adopters and this attribute was studied under two sub-heads i.e., Situational compatibility and Physical compatibility.

The perception of the respondents about the 'Situational compatibility' of dairy innovations in the present study is expressed in terms of 'feasible' or 'not feasible' while 'Physical compatibility' was measured in terms of the needs of the clientele and is expressed as 'necessary' or 'unnecessary' through the scale developed by Nityasree and Siddaramaiah (1996).

\section{Results and Discussion}

The results pertaining to the perception of dairy farmers regarding complexity of recommended dairy technologies were presented in Table 1 and Figure 1, which depict that almost all the dairy farmers perceived the innovation package of practices for rearing heifers, pregnant and lactating animals as simple (97.5\%) and adaptable $(90.88 \%)$ while the practice formulation and feeding of complete feed blocks was perceived to be complex $(65 \%)$ and unadaptable $(59.17 \%)$ by majority of the dairy farmers which is in concurrence with the findings of Nehete (2010).

Feeding of area specific mineral mixture was felt simple $(96.4 \%)$ and adaptable $(88.3 \%)$ by almost all the dairy farmers. The technology cultivation and feeding of hydroponic fodder was felt complex $(97.78 \%)$ and unadaptable $(96.7 \%)$ by almost all the respondents while strategies for enhancement of milk yield and quality were felt simple by more than half (52.3\%) of the respondents and adaptable by nearly $2 / 3^{\text {rds }}(62 \%)$ of the dairy farmers respectively (Lemma $\mathrm{F}$ and Trivedi M.M 2012). The technology of using milking machine was perceived to be complex $(85.56 \%)$ and unadaptable $(88 \%)$ by majority of the dairy farmers while cultivation and feeding of Azolla was felt simple (85\%) and adaptable by majority $(93.89 \%)$ of the dairy farmers which gained the support of Gebremedhin et al., (2003).

Use of ICT's in adoption and diffusion of dairy technologies was perceived to be simple by majority ( $88 \%$ ) of the dairy farmers and adaptable by $3 / 4^{\text {th }}(74.17 \%)$ of the respondents respectively. Marketing strategies to improve milk sales were found to be complex $(90 \%)$ and unadaptable $(65.9 \%)$ by majority of the dairy farmers. 
Table.1 Distribution of respondents according to their perception about complexity of dairy technologies

\begin{tabular}{|c|c|c|c|c|c|c|c|c|c|c|c|c|c|c|c|c|c|c|c|c|}
\hline \multirow{3}{*}{\multicolumn{2}{|c|}{ S.No. }} & \multirow[t]{3}{*}{ Category } & \multicolumn{18}{|c|}{ Innovations } \\
\hline & & & \multicolumn{2}{|c|}{1} & \multicolumn{2}{|c|}{2} & \multicolumn{2}{|c|}{3} & \multicolumn{2}{|c|}{4} & \multicolumn{2}{|c|}{5} & \multicolumn{2}{|c|}{6} & \multicolumn{2}{|c|}{7} & \multirow{2}{*}{$\begin{array}{l}\mathbf{8} \\
\mathbf{N}\end{array}$} & \multirow[b]{2}{*}{$\%$} & \multirow{2}{*}{$\begin{array}{l}9 \\
\mathbf{N}\end{array}$} & \multirow[b]{2}{*}{$\%$} \\
\hline & & & $\mathbf{N}$ & $\%$ & $\mathbf{N}$ & $\%$ & $\mathbf{N}$ & $\%$ & $\mathbf{N}$ & $\%$ & $\mathbf{N}$ & $\%$ & $\mathbf{N}$ & $\%$ & $\mathbf{N}$ & $\%$ & & & & \\
\hline \multirow[t]{2}{*}{1} & \multirow{2}{*}{$\begin{array}{l}\text { Cognitive } \\
\text { complexity }\end{array}$} & Simple & 351 & 97.5 & 126 & 35 & 347 & 96.4 & 8 & 2.22 & 188 & 52.3 & 52 & 14.44 & 306 & 85 & 317 & 88 & 36 & 10 \\
\hline & & Complex & 9 & 2.5 & 234 & 65 & 13 & 3.6 & 352 & 97.78 & 172 & 47.7 & 308 & 85.56 & 54 & 15 & 43 & 12 & 324 & 90 \\
\hline \multirow[t]{2}{*}{2} & \multirow{2}{*}{$\begin{array}{l}\text { Application } \\
\text { complexity }\end{array}$} & Adaptable & 327 & 90.88 & 147 & 40.83 & 318 & 88.33 & 12 & 3.33 & 62 & 17.2 & 44 & 12.22 & 338 & 93.89 & 267 & 74.17 & 123 & 34.1 \\
\hline & & Un Adaptable & 33 & 9.16 & 213 & 59.17 & 42 & 11.67 & 348 & 96.67 & 298 & 82.8 & 316 & 87.78 & 22 & 6.11 & 93 & 25.83 & 237 & 65.9 \\
\hline
\end{tabular}

1 - Package of practices for rearing, heifers, pregnant and lactating animals

2 - Formulation and feeding of complete feed blocks.

3 - Feeding of area specific mineral mixture.

4 - Cultivation and feeding of hydrophonic fodder.

5 - Cultivation and feeding of Azolla.

6 - Strategies for enhancement of milk yield and quality.

7 - Use of milking machine.

8 - Marketing strategies to improve milk sales.

9 - Use of information and communication technologies for adoption and diffusion of innovations.

$\mathrm{N}$ - Frequency $\%$ - Percentage

Fig. 1: Distribution of respondents according to their

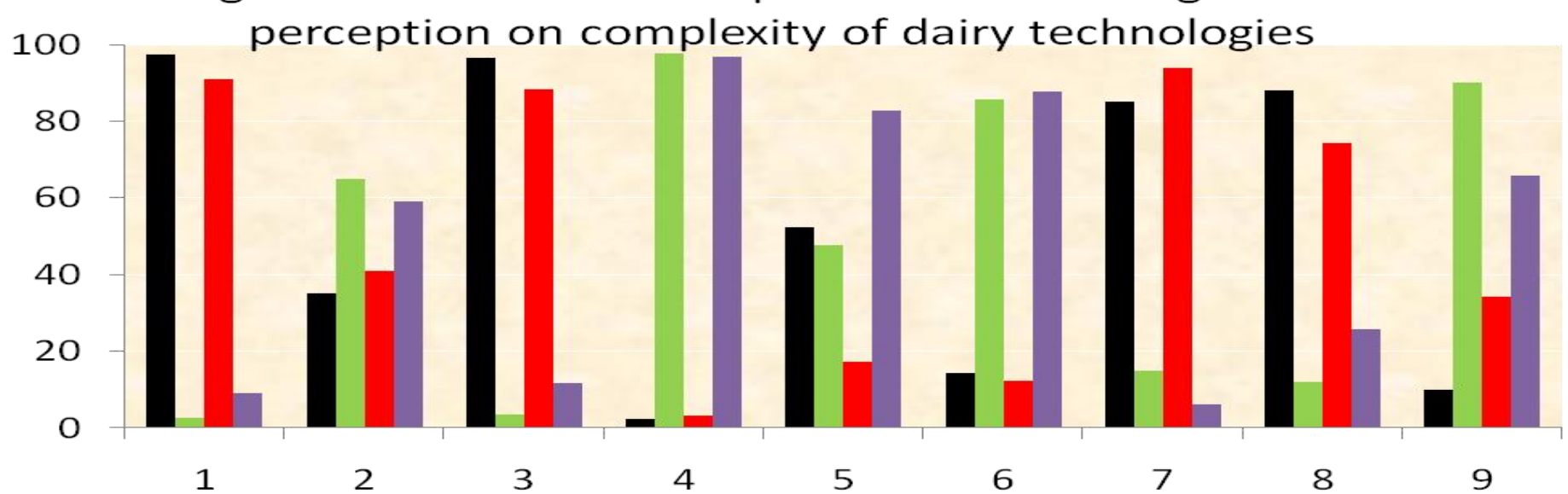

- Cognitive complexity Simple 5 Cognitive complexity Complex 9

Application complexity Adaptable Axis Tițfeplication complexity Unadaptable

Fig.1 Distribution of respondents according to their perception on complexity of dairy technologies 
The results presented in Table 1, indicated that the recommendations package of practices for rearing heifers, pregnant and lactating animals; feeding of area specific mineral mixture; strategies for enhancement of milk yield and quality; cultivation and feeding of azolla and use of ICT's in adoption and diffusion of dairy technologies were perceived to be simple and adaptable by majority of the dairy farmers.

All these technologies were viewed simple and adaptable due to lack of complicated technicalities, perceived need by the farmers and also due to the observability of results in the qualitative as well as economic terms. Vast experience, sound knowledge, technical expertise in dairy farming, accessibility to inputs and exposure to mass media are also some of the reasons that could be attributed to the dairy farmers to perceive the above practices as simple and adaptable.

The recommendations like formulation and feeding of complete feed blocks, technology of using milking machine, technology of cultivation and feeding of hydroponic fodder and marketing strategies to improve milk sales were found to be complex and unadaptable by a sizeable section of the respondents. Expensive operational costs, lack of skills in use of these technologies made them complex and unadaptable. Perception is organization and interpretation of sensory information in order to understand given situation. The study concluded that, the perception of the dairy farmers on complexity of recommended innovations was medium to low. Though the recommended dairy production technologies have been advocated for the past several years, significant breakthrough could not be achieved in improving the perception. Reduction in the operational costs, improvising the skills through hands on training, technical advice by the extension functionaries through mobile phones/what's app, extensive trainings, demonstrations and publicity through mass media may be intensified to make the farmers acquainted and adopt the practices.

\section{References}

Gebremedhin B, Ahmed M. M and Ehui S.K 2003. Determinants of adoption of improved forage technologies in croplivestock mixed systems: Evidence from the highlands of Ethiopia. Tropical Grasslands, 37:262-273.

Lemma F and Trivedi M.M 2012. Extent of adoption of improved dairy husbandry practices in Adaa district of Oromia state, Ethiopia. Wudpecker Journal of Agricultural Research, 1(6): 203-207.

Nehete N.C 2010. Management efficiency of milk producers in Anandtaluka of Gujarat State, M.Sc., (Thesis), Unpublished, APAU, Anand.

Nityasree D.A and Siddaramaiah B.S 1996. A scale to measure the perception of attributes of innovation. Tropical Agricutural Research, 8 pp 55-63.

Rogers E.M. Diffusion of innovations, $5^{\text {th }}$ edition, New York, Free Press, 2003.

\section{How to cite this article:}

Triveni, G., G. R. K. Sharma, Ch. Satyanarayana, K. Sarjan Rao and Raghunandhan, T. 2020. Role of the Attribute Complexity in Adoption of Selected Dairy Innovations. Int.J.Curr.Microbiol.App.Sci. 9(04): 1340-1343. doi: https://doi.org/10.20546/ijcmas.2020.904.159 